\title{
Criptococose pulmonar granulomatosa em um eqüino
}

\author{
Granulomatous cryptococcal pneumonia in a horse
}

\section{Glaucia Denise Kommers ${ }^{1}$ Tatiana Melo de Souza ${ }^{2}$ Marione de Albuquerque Moreira Souto $^{2}$ Flávio Desessards de La Corte ${ }^{3}$ Claudio Severo Lombardo de Barros ${ }^{4}$}

\section{RESUMO}

\begin{abstract}
Descreve-se um caso de pneumonia granulomatosa por Cryptococcus neoformans em um eqüino, macho, Quarto de Milha, de 8 anos de idade com história de laminite crônica por 2 anos. Na necropsia, havia múltiplos nódulos macios e gelatinosos distribuídos aleatoriamente nos pulmões. Histologicamente, observaram-se cavidades císticas preenchidas por numerosas estruturas leveduriformes circundadas por um espesso halo claro e por reação inflamatória granulomatosa leve. Em seções coradas por azul alciano e PAS, observou-se densa cápsula mucinosa circundando estruturas leveduriformes com morfologia típica de C. neoformans.
\end{abstract}

Palavras-chave: Cryptococcus neoformans, eqüinos, pneumonia, patologia.

\section{ABSTRACT}

A case of cryptococcal granulomatous pneumonia is described in an 8-year-old, male, Quarter Horse with chronic laminitis of 2 years duration. Multiple soft gelatinous nodules were randomly distributed in the lungs. Microscopically, there were cavities filled with numerous yeast-like organisms surrounded by a clear halo and evoking a mild granulomatous reaction. An Alcian blue- and PAS-positive mucinous capsule surrounded the yeast-like structures morphologically typical of Cryptococcus neoformans.
Key words: Cryptococcus neoformans, equine, pneumonia, pathology.

A criptococose tem distribuição mundial e afeta pessoas e animais; o gato é a espécie doméstica mais comumente afetada. A infecção é adquirida por inalação de poeira contaminada e afeta principalmente o sistema respiratório, mas pode ocasionalmente ocorrer de forma disseminada (DUNGWORTH, 1993). Em cavalos, a infecção por C. neoformans tem sido associada principalmente à meningite (STECKEL et al., 1982), encefalite (CHO et al., 1986), granuloma nasal (ROBERTS et al., 1981), pneumonia (PEARSON et al., 1983; RILEY et al., 1992) e aborto com placentite micótica e pneumonia no feto (RYAN \& WYAND, 1981).

Descreve-se aqui um caso de criptococose pulmonar granulomatosa como achado incidental de necropsia em um eqüino, macho, Quarto de Milha, de 8 anos de idade com histórico de laminite crônica por 2 anos e de ter sido tratado com corticosteróides por tempo prolongado. $\mathrm{O}$ animal foi submetido ao exame

${ }^{1}$ Departamento de Patologia, Seção de Patologia Veterinária, Centro de Ciências da Saúde (CCS), Universidade Federal de Santa Maria (UFSM), 97105-900, Santa Maria, RS, Brasil. E-mail: glaukommers@yahoo.com. Autor para correspondência.

${ }^{2}$ Programa de Pós-graduação em Medicina Veterinária - área concentração em Patologia Veterinária, UFSM, Santa Maria, RS, Brasil.

${ }^{3}$ Departamento de Clínica de Grandes Animais, Centro de Ciências Rurais (CCR), UFSM, Santa Maria, RS, Brasil.

${ }^{4}$ Departamento de Patologia, Seção de Patologia Veterinária, CCS, UFSM, Santa Maria, RS, Brasil. 
clínico onde foram constatados abscessos em ambos os cascos anteriores, perda parcial de tecido córneo com rotação da terceira falange e higromas de pressão no tecido subcutâneo de ambos os cotovelos. O cavalo foi submetido à eutanásia devido ao mau prognóstico.

Na necropsia, observou-se péssimo estado corporal, com ambos os cascos dos membros anteriores frouxos e osteomielite supurativa com destruição parcial da segunda e terceira falanges. Higromas de pressão foram confirmados no tecido subcutâneo de ambos os cotovelos. Nos pulmões, havia múltiplos nódulos com $0,5-3,0 \mathrm{~cm}$ de diâmetro distribuídos aleatoriamente (Figura 1A). Ao corte, esses nódulos eram macios, amarelados e gelatinosos e histologicamente correspondiam a cavidades limitadas por tecido conjuntivo fibroso e preenchidas por numerosas estruturas leveduriformes fracamente basofílicas de 5-10 $\mu \mathrm{m}$ de diâmetro, circundadas por um halo claro de até $30 \mu \mathrm{m}$ de diâmetro (produzido pela cápsula mucinosa não corada) e por poucas células inflamatórias, principalmente macrófagos e linfócitos. Em algumas áreas do parênquima pulmonar, havia reação granulomatosa constituída por macrófagos epitelióides, linfócitos e células gigantes multinucleadas (algumas com leveduras no citoplasma). Pelas colorações do azul alciano (Figura 1B) e do ácido periódico de Schiff (PAS), uma densa cápsula mucinosa foi evidenciada circundando os microrganismos, interpretados como Cryptococcus neoformans.

C. neoformans ocorre no solo, principalmente contaminando fezes de pombos e de outras aves. A infecção geralmente é por inalação do agente em poeiras contaminadas (DUNGWORTH, 1993; SAMUELSON, 1999), resultando em infecção primária do trato respiratório, afetando mais freqüentemente a cavidade nasal do que os pulmões. A infecção pode disseminar-se sistemicamente, atingindo o sistema nervoso central, pele, olhos, linfonodos, dentre outros órgãos (DUNGWORTH, 1993).

Os sinais clínicos em eqüinos com criptococose pulmonar incluem emagrecimento, tosse, epistaxe (RILEY et al., 1992), dispnéia, estertores respiratórios e febre (RYAN \& WYAND, 1981). Radiografias de cavalos com pneumonia por $\boldsymbol{C}$. neoformans revelam áreas radioluscentes multifocais a coalescentes compatíveis com inflamação granulomatosa ou abscedativa, e parece haver predileção pelos lobos caudais (RILEY et al., 1992). Exsudato gelatinoso (flocular ou espesso e amarelo) tem sido observado durante endoscopia traqueal de cavalos afetados. Exames citológicos de lavados traqueais revelaram organismos com morfologia típica de $\boldsymbol{C}$. neoformans quando corados pelo método de Wrigth (PEARSON et al., 1983; RILEY et al., 1992). $\mathrm{Na}$ necropsia, as lesões de criptococose pulmonar consistem de múltiplos focos gelatinosos brancos ou amarelados (DUNGWORTH, 1993), como os vistos no cavalo deste relato, que podem coalescer e substituir grande parte do parênquima pulmonar (PEARSON et al., 1983). Disseminação para linfonodos regionais e mesentéricos também tem sido descrita (PEARSON et al., 1983; RYAN \& WYAND, 1981).

Histologicamente, C. neoformans é um fungo leveduriforme com $\cong 4-8 \mu \mathrm{m}$ de diâmetro circundado por espessa cápsula de polissacarídeos que não se cora pela hematoxilina-eosina, conferindo assim o aspecto característico de "bolhas de sabão". A cápsula é visualizada histologicamente pelas colorações de PAS, azul alciano ou mucicarmina. Polissacarídeos da cápsula conferem o aspecto gelatinoso observado nas lesões macroscópicas (DUNGWORTH, 1993). A morfologia típica do fungo (PEARSON et al., 1983; RIAN \& WYAND, 1981) permite o diagnóstico definitivo de criptococose pela microscopia (DUNGWORTH, 1993; STECKEL et al., 1982). Brotamentos de base estreita são ocasionalmente vistos nas lesões de criptococose (CHO et al., 1986; PEARSON et al., 1983; RIAN \& WYAND, 1981). Esfregaços do material gelatinoso fresco corados pela tinta Nanquim demonstraram a coloração negativa da cápsula (DUNGWORTH, 1993).

Em humanos, a resposta tecidual à presença de $\boldsymbol{C}$. neoformans é extremamente variável. Em indivíduos imunossuprimidos (AIDS; após transplantes de órgãos), a reação inflamatória pode estar ausente, permitindo o crescimento de massas gelatinosas do fungo nos tecidos. Em pacientes com imunossupressão grave, a infecção pode se disseminar para a pele, órgãos parenquimatosos e ossos. Em indivíduos imunocompetentes ou com doença prolongada, o fungo induz uma reação granulomatosa composta por macrófagos, linfócitos e células gigantes multinucleadas (SAMUELSON, 1999).

$\mathrm{Na}$ criptococose humana, a virulência do agente tem sido relacionada à cápsula de polissacarídeos, à inibição da ação de macrófagos alveolares e à produção de fenol oxidase, uma enzima que protege o fungo do sistema oxidativo da epinefrina do hospedeiro (SAMUELSON, 1999). Destaca-se o papel dos polissacarídeos capsulares (glucuronoxiloman [GXM], galactoxilomanan [GalXM] e manoproteínas [MPs]), que apresentam vários efeitos imunomodulatórios na resposta do hospedeiro, tais 


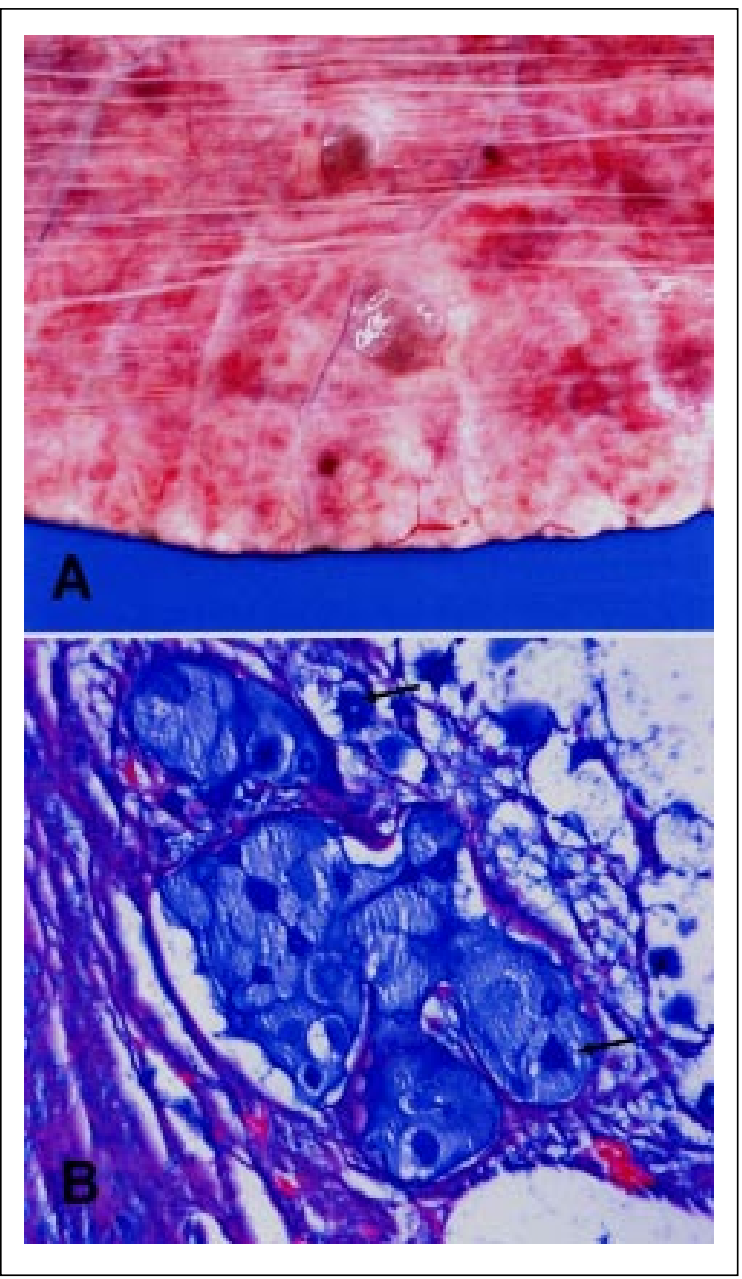

Figura 1 - Eqüino, pulmão, pneumonia granulomatosa por Cryptococcus neoformans. A - Há dois nódulos salientes, gelatinosos e amarelados. B - Leveduras circundadas por densa cápsula de polissacarídeos azul alciano - positiva (setas). Coloração de azul alciano. Obj. 20.

como a inibição da fagocitose, supressão da imunidade mediada por células $\mathrm{T}$ e a indução de tolerância imunogênica (ELLERBROEK et al., 2004).

Em animais, uma resposta inflamatória celular marcada não é típica, geralmente consistindo de poucos macrófagos, linfócitos e plasmócitos (CHO et al., 1986; DUNGWORTH, 1993; RYAN \& WYAND, 1981). As lesões pulmonares podem tornarse mais tipicamente granulomatosas, contendo células epitelióides (DUNGWORTH, 1993) e células gigantes multinucleadas (DUNGWORTH, 1993; STECKEL et al., 1982), como vistas em algumas seções do pulmão do cavalo deste relato.
A criptococose ocorre mais comumente em animais com queda na imunidade local ou sistêmica. Fatores como debilidade, desnutrição, uso prolongado de corticosteróides e infecções virais (por ex., pelos vírus da imunodeficiência e da leucemia felinas) têm sido associados a criptococose em animais (DUNGWORTH, 1993). Num relato de criptococose em sete cavalos, cinco tinham história de doenças que podem tê-los predisposto à criptococose (RILEY et al. 1992). No cavalo deste relato, a laminite crônica e o uso prolongado de corticosteróides podem ter sido os fatores predisponentes. Entretanto, C. neoformans pode também infectar cavalos imunocompetentes (PEARSON et al., 1983).

Os achados macroscópicos e microscópicos observados no cavalo deste estudo são típicos de pneumonia granulomatosa causada por $\boldsymbol{C}$. neoformans. A ausência de sinais clínicos pode ser explicada pelo comprometimento limitado a pequenas áreas do pulmão, quando o animal foi submetido à eutanásia e necropsiado.

\section{REFERÊNCIAS}

CHO, D.Y. et al. Cerebral cryptococcosis in a horse. Vet Pathol, v.23, p.207-209, 1986.

DUNGWORTH, D.L. The respiratory system. In: JUBB, K.V.F. et al. Pathology of domestic animals. 4.ed. San Diego : Academic, 1993. V.2, 747p. Cap.6, p.667-668.

ELLERBROEK, P.M. et al. Effects of the capsular polysaccharides of Cryptococcus neoformans on phagocyte migration and inflammatory mediators. Curr Med Chem, v.11, p.253-266, 2004.

PEARSON, E.G. et al. Cryptococcal pneumonia in a horse. $\mathbf{J}$ Am Vet Med Assoc v.183, p.577-579, 1983.

RILEY, C.B. et al. Cryptococcosis in seven horses. Aust Vet J, v.69, p.135-139, 1992.

ROBERTS, M.C. et al. A protracted case of cryptococcal nasal granuloma in a stallion. Aust Vet J, v.57, p.287291, 1981.

RYAN, M.J.; WYAND, D.S. Cryptococcus as a cause of neonatal pneumonia and abortion in two horses. Vet Pathol, v.18, p.270-272, 1981.

SAMUELSON, J. Infectious disease. In: COTRAN, R.S. et al. Robbins - Pathological basis of disease. 6.ed. Philadelphia: Saunders, 1999. Cap.9, p.379-380.

STECKEL, R.R. et al. Antemortem diagnosis and treatment of crytococcal meningitis in a horse. J Am Vet Med Assoc, v.180, p.1085-1089, 1982. 